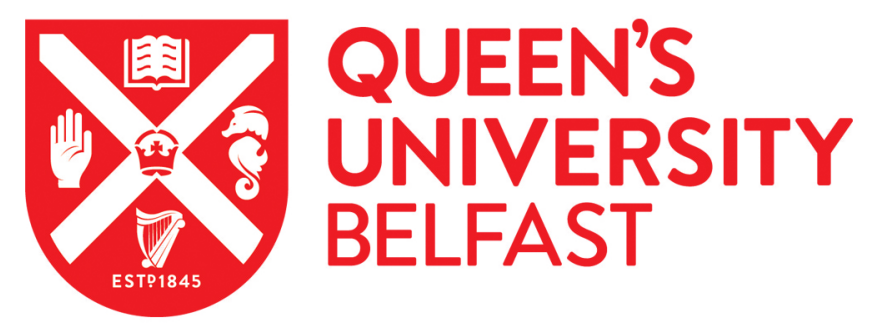

\title{
Comparing Shame in Clinical and Nonclinical Populations: Preliminary Findings
}

Dyer, K. F. W., Dorahy, M. J., Corry, M., Black, R., Matheson, L., Coles, H., Curran, D., Seager, L., \& Middleton, W. (2016). Comparing Shame in Clinical and Nonclinical Populations: Preliminary Findings. Psychological trauma : theory, research, practice and policy. https://doi.org/10.1037/tra0000158

Published in:

Psychological trauma : theory, research, practice and policy

Document Version:

Peer reviewed version

Queen's University Belfast - Research Portal:

Link to publication record in Queen's University Belfast Research Portal

Publisher rights

Copyright 2016 APA.

This article may not exactly replicate the final version published in the APA journal. It is not the copy of record.

\section{General rights}

Copyright for the publications made accessible via the Queen's University Belfast Research Portal is retained by the author(s) and / or other copyright owners and it is a condition of accessing these publications that users recognise and abide by the legal requirements associated with these rights.

Take down policy

The Research Portal is Queen's institutional repository that provides access to Queen's research output. Every effort has been made to ensure that content in the Research Portal does not infringe any person's rights, or applicable UK laws. If you discover content in the Research Portal that you believe breaches copyright or violates any law, please contact openaccess@qub.ac.uk. 


\section{Comparing shame in clinical and non-clinical populations: Preliminary findings}

Kevin F. W. Dyer ${ }^{1,2}$, Martin J. Dorahy ${ }^{3,4}$, Mary Corry ${ }^{5}$, Rebecca Black ${ }^{6}$, Laura Matheson ${ }^{1}$, Holly Coles $^{1}$, David Curran ${ }^{1}$, Lenaire Seager ${ }^{4}$, \& Warwick Middleton ${ }^{4}$

${ }^{1}$ School of Psychology, Queen’s University Belfast, Northern Ireland

${ }^{2}$ Psychological Therapies Service, Northern HSC Trust, Northern Ireland

${ }^{3}$ Department of Psychology, University of Canterbury, Christchurch, New Zealand

${ }^{4}$ The Cannan Institute, Belmont Private Hospital, Brisbane, Australia

${ }^{5}$ Trauma Resource Centre, Everton Complex, Belfast HSC Trust, Northern Ireland ${ }^{6}$ SET Connects, South Eastern HSC Trust, Northern Ireland

Address correspondence to:

Kevin F. W. Dyer, School of Psychology, DClinPsych, David Keir Building, 18-30 Malone Road, Belfast, BT9 5NP, Northern Ireland. Tel: 02890 975632, Fax: 02890 975486; Email: k.dyer@qub.ac.uk.

Martin J. Dorahy, Department of Psychology, University of Canterbury, Christchurch, New Zealand. Tel: +64 3364 3416, Fax: +64 3364 2181; Email: martin.dorahy@canterbury.ac.nz. 
Running Head: Shame in clinical and non-clinical populations

Word count: 6920 (including references and tables)

\section{Acknowledgements}

The authors would like to thank the study participants and clinical staff who assisted with data collection. We would like to specifically thank Kevin Webb, Maria Shannon, Brian McDermott, and Margaret Ryan for their contribution to this research. 
Objectives: To conduct a preliminary study comparing different trauma and clinical populations on types of shame coping style and levels of state shame and guilt.

Methods: A mixed independent groups/correlational design was employed. Participants were recruited by convenience sampling of three clinical populations, namely Complex Trauma (n = 65), DID $(n=20)$, General Mental Health $(n=41)$, and a control group of Healthy Volunteers $(\mathrm{n}=125)$. All participants were given 1) the Compass of Shame Scale, which measures the four common shame coping behaviours/styles of "withdrawal”, "attack self”, "attack other" and "avoidance"; and 2) the State Shame and Guilt Scale, which assesses state shame, guilt and pride.

Results: The DID group exhibited significantly higher levels “attack self”, “withdrawal”, and “avoidance” relative to the other groups. The Complex Trauma and General Mental Health groups did not differ on any shame variable. All three clinical groups had significantly greater levels of the "withdrawal” coping style and significantly impaired shame/guilt/pride relative to the healthy volunteers. “Attack self” emerged as a significant predictor of increased state shame in the Complex Trauma, General Mental Health, and Healthy Volunteer groups, whereas "withdrawal” was the sole predictor of state shame in the DID group.

Conclusions: DID emerged as having a different profile of shame processes compared to the other clinical groups, whereas the Complex Trauma and General Mental Health groups had comparable shame levels and variable relationships. These differential profiles of shame coping and state shame are discussed with reference to assessment and treatment.

Keywords: Shame, guilt, PTSD, complex trauma, dissociative identity disorder, coping style 
Comparing shame in clinical and non-clinical populations: Preliminary findings

Shame is an emotion that has emerged as a factor of growing clinical relevance. Whereas the more familiar "basic” emotions (e.g., sadness, happiness) are culturally universal, primal feelings that emerge in early infancy, self-conscious emotions like shame are viewed as more elaborate emotional reactions that are closely associated with complex socio-cognitive processes such as self-awareness and self-evaluation. Although both shame and guilt are self-conscious emotions, they represent distinct clinical concepts that emerge in reaction to perceived or actual negative events. Shame responses comprise primarily negative, global, stable evaluations of the self (e.g., " $I$ am a bad person”) whereas guilt is represented by negative, specific, transient, situational evaluations about actions/behaviours (e.g., "I did a bad thing today”; Tangney \& Dearing, 2002; Wong \& Tsai, 2007). Such a differentiation, while ostensibly subtle, can have substantial implications for psychopathology. Several studies have found that shame rather than guilt is a significant risk factor for the onset and maintenance of mental health difficulties (Leskela, Dieperink, \& Thuras, 2002; Robinaugh \& McNally, 2010). Moreover, it has been theorised that guilt is actually an adaptive response in which movement from shame to guilt represents a stage of mental health recovery (Tangney, Steuwig, \& Mashek, 2007).

For the most part, the weight of research examining shame as a risk factor for psychological difficulties centres on trauma populations. Understandably, traumatic events, particularly ones that involve profound threats to self-appraisals and self-concept (e.g., childhood abuse, assault) have been found to evoke acute shame responses and altered selfperception (Dyer, Dorahy, Shannon, \& Corry, 2013; Srinivas, DePrince, \& Chu, 2015). In turn, post-traumatic shame is a notable risk factor for development and maintenance of posttraumatic stress disorder (PTSD; Oktedalen, Hoffart, \& Langkaas, 2015). 
The impact of shame on complicated trauma-related presentations, such as Complex PTSD and Dissociative Identity Disorder (DID) is considered to be more profound (Herman, 2015). Complex PTSD refers to a constellation of six trauma symptoms (e.g., altered selfperception, somatisation) that extend beyond the standard PTSD symptom clusters (Pelcovitz et al., 1997). Although not an accepted diagnosis in current taxonomies, Complex PTSD, or its less stringent formulation of Complex Trauma, is a clinically useful conceptualisation that is argued to develop as a result of chronic, repeated traumatic events (e.g., childhood sexual abuse, torture; Courtois \& Ford, 2009; Herman, 1992). Shame and guilt are considered central perpetuating emotional processes in Complex PTSD (e.g., Dorahy, 2010). In a chronic, complex trauma sample, Dyer et al. (2013) found that altered self-perceptions, including shame, were significant mediating factors in the mechanism linking childhood trauma to later psychopathology (e.g., hostility, self-harm). DID also has strong theoretical associations with both a history of complex trauma and shame (Chu, 2011; Dorahy, Middleton, Seager, McGurrin, Williams, \& Chambers, 2015). Overwhelming evidence supports the link between childhood trauma and DID onset (Dalenberg et al., 2012; Dorahy et al., 2015). In individuals with DID, it has been hypothesized that the shame, fear and other emotional reactions to severe trauma leads to fragmentation of the self into dissociative identities as a way of coping with the aversive memories and feelings (Putnam, 2006). In this way, shame reactions to trauma can be regarded as one of several interacting catalysts of DID symptoms.

Although the majority of research into shame, guilt and psychopathology focusses on the emergence of these self-conscious emotions in reaction to clearly defined traumata and posttraumatic sequelae, there is a growing body of evidence highlighting that shame and guilt plays a more generic role in wider psychological difficulties such as generalised anxiety, OCD, social anxiety, and depression, even in the absence of a significant "traumatic event" 
(Fergus, Valentiner, Mcgrath, \& Jencius, 2010; Kim, Thibodeau, \& Jorgensen, 2014). Luby et al. (2013) found that shame and guilt were significant risk factors for depression in children as young as three years of age. Black, Curran, and Dyer (2013) also reported that shame coping styles were significant predictors of relationship depression and functioning in a general mental health sample.

The proposed transdiagnostic role of shame - and to a lesser extent guilt - in mental health presentations has led a number of researchers to develop generic theoretical models and treatment protocols for shame. Gilbert’s (2002) evolutionary and biopsychosocial model of shame and Nathanson’s (1992) Compass of Shame, which builds on Tomkins (1963) seminal work, assert that shame-proneness as a trait emerges from early childhood relationship factors (e.g., attachment style). How an individual experiences important formative relationship in terms of acceptance, safety, and evaluation will in turn affect how they regulate their own internal processes and evaluate themselves. Incestuous childhood sexual abuse, for example, results not only in the emergence of a clear trauma that may impact on self-appraisals of being damaged and shameful, but it also introduces a negative model in the child's mind of how loved ones evaluate them, thus leading them to feel further shame because they perceive themselves as worthless, unlovable, and unsafe (Finkelhor \& Browne, 1985). In response to such aversive shame cognitions/emotions, Nathanson (1992) asserted that people manage this affect by adopting four potential coping styles, behavioural scripts or strategies, namely “attack self, “attack other”, “withdrawal”, or “avoidance”. These strategies can be maladaptive and unhelpful, particularly if rigidly or excessively used.

Whilst shame is considered a pervasive contributor to mental health problems, with a wide-reaching influence that extends beyond trauma-related clinical presentations, there are some notable omissions in the knowledge base. Most significantly, only one study has compared levels of state shame/guilt or defensive responses to shame in different trauma and 
mental health groups (i.e., Dorahy et al., 2015). Dorahy and colleagues found that their mixed Dissociative Disorders group had similar levels of shame coping styles and state shame relative to their abuse-related Chronic PTSD sample, but significantly greater levels than their Mixed Psychiatric group. No comparisons, however, were made between the Chronic PTSD and Mixed Psychiatric groups. Additionally, personality theory would hold that stable traits (e.g., characterological factors, consistent behaviour patterns) can predict transient mood responding (Cooper, 2010; Petrides \& Furnham, 2003). However, no study has explored how stable, underlying patterns of shame coping affect shame states. Understanding which shame coping styles increase the risk of heightened state shame and how these processes differ between clinical populations would be clinically useful.

The present study aimed to conduct a preliminary investigation of these highlighted research gaps by comparing two trauma-related mental health groups normally associated with severe shame and guilt reactions (i.e., DID and Complex Trauma), a general mental health group of mixed presentations (e.g., depression, anxiety), and a baseline control group of healthy volunteers on shame coping strategies, and state shame and guilt. Separate group regression analyses were also to be completed to identify how underlying shame coping styles impact upon state shame responding. It was hypothesised that DID and Complex Trauma groups would have significantly greater levels of state shame and guilt and unhelpful shame coping strategies compared to the General Mental Health and Healthy Volunteer groups. Secondly, it was asserted that shame coping styles would significantly predict levels of state shame in the four participant groups.

\section{Method}

\section{Participants}


A convenience sample of 251 participants was obtained, comprising 4 groups: 1) Dissociative Identity Disorder (DID; $n=20) ; 2$ ) Complex Trauma ( $=65)$; 3) General Mental Health ( $\mathrm{n}=41)$; and 4) Healthy Volunteer $(\mathrm{n}=125)$.

The DID group was recruited from a trauma and dissociative disorder treatment program in Brisbane, Australia. All DID participants had a psychiatrist diagnosis of DID and an independently assessed DID diagnosis from the Dissociative Disorders Interview Schedule (Ross et al., 1989). All participants were female and had a mean age of 45.60 years (SD = 9.41).

The Complex Trauma group was obtained from a trauma therapy service in Belfast, Northern Ireland, which serves people suffering psychological problems resulting from exposure to the Northern Irish conflict (e.g., bombings, sectarian violence). A sample of 65 individuals (44 males; 21 females) with a mean age of $40.43(\mathrm{SD}=12.42)$ was recruited from a total of 154 service-users. Participants in this group had a clinician-assessed diagnosis of chronic PTSD, with symptoms present for more than 3 months. All participants had multiple traumatic experiences $(\geq 2)$ and $95 \%$ of this group reported clinically "High" levels of complex PTSD symptoms as measured by the Stress Reactions Checklist (Ford et al., 2007). Due to the well-established prolonged, repeated traumata associated with the Northern Irish conflict (see Dorahy et al., 2009; Ferry et al., 2015), and the trauma/symptom characteristics of the current sample, this group may be reliably categorised as a chronic, complex trauma sample. Further details on sample characteristics can be found in Dorahy et al. (2013).

The general mental health group was composed of 19 (46\%) female and 22 (54\%) male participants, ranging in age from 21 to 67 years old $(M=41.29, \mathrm{SD}=12.46)$. All participants were attending an adult mental health service for therapy and presented with a variety of generic mild - moderate mental health difficulties. Therapists of participants used assessment information, DSM-IV (American Psychiatric Association [APA], 1994), and 
clinical judgement to informally diagnose the main presenting problems of participants. This sample has been described previously in Black et al. (2013); however, nine participants who reported trauma and/or clinical PTSD symptoms were excluded from the present study to prevent overlap with the Complex Trauma Group. Of the 41 participants, 19 had mood problems (e.g., Major Depression); 10 had anxiety disorders (e.g., Generalised Anxiety Disorder); and 12 had personality problems (e.g., Borderline Personality disorder).

The Healthy Volunteers sample was made up of an opportunity sample of 125 male and females aged 18 - 50 years old recruited via a university online research participation database and community advertising. A processing error meant mean age was not logged for this sample.

\section{Materials/Apparatus}

The Compass of Shame Scale (COSS; Elison, Lennon \& Pulos, 2006) measures four common shame coping behaviours/styles (i.e., “withdrawal”, “attack self”, “attack other” and “avoidance”) originally outlined in Nathanson’s (1992) Compass of Shame model. Participants provide ratings on a five-point Likert scale indicating how frequently they would use each behaviour in 12 hypothetical shame scenarios. "Withdrawal” represents active attempts to escape from shame stimuli either physically or emotionally. “Attack self” represents inwardly directed anger, self-criticism, self-disgust, and frustration in response to shame stimuli. "Attack other” is a similar anger-related reaction to evoked shame, with the exception that the emotion is directed onto an external object or person. The "avoidance" style is akin to the defence mechanisms of denial or repression, where the individual has a tendency to distort or minimise the shame experience in order to avoid the aversive feeling. Construct validity of the scale has been supported (i.e., Elison et al., 2006) and internal consistency for the four coping behaviours ranged between 0.79 and 0.95 in the current study. 
State shame, state guilt, and state pride were measured using the 15-item State Shame and Guilt Scale (SSGS; Marschall, Sanftner \& Tangney, 1994). Responses are made on a 5point scale from 1 (not at all) to 5 (very strongly). Cronbach's alpha values for shame (0.86), guilt (0.90), and pride (0.87) were highly acceptable in the present investigation and comparable with the original validation studies (Marschall et al., 1994).

\section{Procedure}

All three clinical groups (i.e., DID, Complex Trauma, General Mental Health) were recruited by a similar methodology. Participants were provided an information sheet about the investigation by their therapist with a reply slip attached. Individuals interested in taking part returned the reply slip with their contact details. Research team contact details were also available on the university online research system and local advertising. These materials provided healthy volunteers with information on how to approach the researchers for participation. A member of the research team contacted both clinical and non-clinical participants and arranged a meeting to complete the study questionnaire measures via interview. Informed consent was also obtained during this session. The relevant ethics committees granted approval.

\section{Results}

\section{Demographic/Clinical information}

There was no demographic information available for the Healthy Volunteer group aside from age range. However, age and gender characteristics were available for the DID, Complex Trauma and General Mental Health samples. Marital status was also available for the DID and General Mental health groups. Table 1 summarises the sample composition on these variables.

ANOVA revealed that there were no significant differences between the DID, Complex Trauma and General Mental health groups on age, $F(2,123)=1.43 ; p=.24$; Partial 
$\eta^{2}=0.02$; Power $=30 \%$. Chi square analyses with Fischer's Exact test also indicated no differences between the DID and General Mental Health groups on marital status, $\chi^{2}(2, N=$ $61)=2$; exact $p=.38 ; \varphi=0.18$. Nevertheless, the groups did differ on gender primarily due to the DID group being exclusively female, and the healthy volunteer groups being skewed to female. The other two clinical groups had a similar gender balance.

In order to ascertain if the demographic/clinical factors of gender and marital status were a confounding influence, exploratory ANOVAs were conducted with a randomlyselected shame variable as the dependent variable and gender and marital status as independent variables. Similarly, age was correlated with the shame variable to see if it moderated shame responding in the DID and General Mental Health groups. COSS “attack self” emerged as the randomly-selected variable. However, no significant differences were found between gender or marital status on "attack self” and there was no significant correlations between age and COSS “attack self” in any of the relevant groups ( $>.05)$.

Insert Table 1 about here

\section{Shame Differences}

Table 2 displays the means and standard deviations for the participant groups on all COSS and SSGS subscales.

Insert Table 2 about here 
Two MANOVAs were performed comparing the participant groups on 1) state shame, guilt, and pride (SSGS subscales); and 2) shame coping styles (COSS subscales). Post-hoc Bonferroni comparisons were conducted to explore pairwise group differences on individual variables. Significant differences between groups on paired comparisons have been flagged in Table 2.

State shame, guilt and pride. An overall multivariate effect was found across group on state measures, $F(9,596)=12.11 ; p<.001$; Wilk's Lamda $=.67$; Partial $\eta^{2}=.13$; Power $=100 \%$. This significance was produced by univariate differences between groups on state shame, $F(3,247)=32.01 ; p<.001$; Partial $\eta^{2}=.28$; Power $=100 \%$, guilt, $F(3,247)=$ 20.78; $p<.001 ;$ Partial $\eta^{2}=.2$; Power $=100 \%$, and pride, $F(3,247)=26.38 ; p<.001$; Partial $\eta^{2}=.24$; Power $=100 \%$.

In post hoc paired comparisons, all three clinical groups (i.e., DID, Complex Trauma, General Mental Health) had significantly greater levels of state shame, and guilt, and significant lower levels of state pride compared to the Healthy Volunteers control group ( $\mathrm{p}<$ $.001)$.

Regarding the clinical groups specifically, the DID group had significantly greater levels of state shame compared to the Complex Trauma and General Mental Health groups (p $<$.05). There were no significant differences between the Complex Trauma and General Mental Health groups on any of the state variables. There were also no significant differences in paired comparisons involving the three clinical groups on state guilt. In state pride, the DID group reported significantly lower levels than the General Mental Health group ( $\mathrm{p}$ .05), but not the Complex Trauma group.

Shame coping styles. Overall, there was a significant multivariate effect for groups on shame coping styles $F(12,645)=16.27 ; p<.001$; Wilk's Lamda $=.5$; Partial $\eta^{2}=.21$; Power $=100 \%$. Univariate group differences were evident for "withdrawal”, $F(3,247)=$ 
52.1; $p<.001$; Partial $\eta^{2}=.39$; Power $=100 \%$, “attack self”, $F(3,247)=37.32 ; p<.001$; Partial $\eta^{2}=.31$; Power $=100 \%$, and “avoidance”, $F(3,247)=16.95 ; p<.001 ;$ Partial $\eta^{2}=$ .17 ; Power $=100 \%$. There was a non-significant trend for group on the "attack other” coping style, $F(3,247)=2.6 ; p=.053 ;$ Partial $\eta^{2}=.03$; Power $=63 \%$.

Paired comparisons found that the DID group scored significantly higher than all three comparison groups on shame "withdrawal”, “attack self”, and "avoidance” coping styles ( $\mathrm{p}<.001)$. There were no significant differences between the Complex Trauma and General Mental Health groups on any of the coping styles. The General Mental Health group scored significantly higher than the Healthy Volunteer group on "withdrawal” ( $\mathrm{p}<.001)$, but not “attack self”, “avoidance”, or “attack other”. The Complex Trauma group, however, reported significantly higher "withdrawal” and "attack self” coping styles compared to the Healthy Volunteer group ( $\mathrm{p}<0.001)$. There were no group differences in any paired comparisons on “attack other” coping style.

\section{Coping Style and State Shame}

In order to explore if certain shame coping styles predicted increased state shame responding in the different clinical groups, the three clinical samples were split and individual separate stepwise regression analyses were completed. The shame coping styles of “withdrawal”, “attack self”, “avoidance”, and “attack other” were inputted as predictors with state shame as the criterion variable. Non-significant predictors were removed automatically to yield the most parsimonious regression models. In all three of the analyses, only one coping style remained in the regression after stepwise variable removal. "Attack self” was a significant predictor of state shame in the Complex Trauma, General Mental Health, and Healthy Volunteer groups accounting for $20 \%, 36 \%$, and $28 \%$ of variance in state shame scores respectively. In the DID group, however, a different shame coping style - 
“withdrawal” - was the sole significant predictor of state shame, accounting for $52 \%$ of variance (see Table 3).

\section{Discussion}

The DID group exhibited the highest levels of state shame and shame coping styles relative to the remaining clinical/control groups, and presented with a distinct shame profile. In contrast to the first hypothesis, the Complex Trauma group had somewhat comparable albeit still elevated - levels of state shame, guilt and pride to the General Mental Health group and utilised similar coping styles. The findings were also unexpected with regard to how shame coping styles predict active state shame reactions in the three groups. The relationship was found to be similar across the Complex Trauma, General Mental Health, and Healthy Volunteer samples, as "attack self” coping style was the sole predictor in all three populations of increased state shame. However, the DID group analyses revealed a different relationship with "withdrawal” emerging as the sole substantial predictor of state shame.

The markedly heightened levels of shame variables in the DID group supports research findings that shame is a significant issue for this population and a prominent barrier to psychological intervention (Chu, 2011). The extent of the differences between the DID group and the Complex Trauma group on state shame and coping styles, however, was greater than recent empirical reports, which found that a mixed dissociative disorders group and chronic trauma group had comparably high shame responses (Dorahy et al., 2015). Some of this disparity may be explained by the differing selection criteria in both studies. For example, the Complex PTSD sample in this study was conflict-related whereas the chronic PTSD sample of Dorahy et al. (2015) was child abuse-related. Moreover, in the present investigation, only individuals with a full formal DID diagnosis were included. Complex features of DID such as multiple identities and dissociative amnesia are viewed as more extreme psychological reactions aimed at assisting an individual in coping with severe trauma 
(Dalenberg et al., 2012). Such responses could be due to the traumatic experiences being appraised as more profoundly destructive to the self. Consequently, in line with the findings here, the DID group may experience greater levels of shame and engage in more shame coping styles because of their exposure to more shame-prone abuse and neglect. In a chronic PTSD sample with high levels of abuse and neglect similar shame levels were found to DID (Dorahy et al., 2015). Moreover, in DID, their established methods of coping (e.g., structural dissociation) exist on a spectrum of avoidance, which are similar to a number of shame coping styles (e.g., “withdrawal”).

The lack of differences between the Complex Trauma group and General Mental Health group in terms of shame factors was also unanticipated and somewhat contrary to the accepted understanding that shame is a particularly potent, notable sequelae of complex traumatic experiences, more so than for individuals with other mental health presentations (e.g., Herman, 2015; Srinivas et al., 2015). Research has begun to identify that shame is a prevalent transdiagnostic factor in multiple mental health presentations (e.g., Fergus et al., 2010; Kim et al., 2014) and it may be that the severity and association between shame states and coping styles in trauma and general mental health populations are more analogous than previously believed. However, it must be acknowledged that the present study focussed narrowly on baseline comparisons of these shame factors and did not examine differences in trait shame or the relationship between shame and symptomatology. While the mechanisms operating between shame coping style and state may be similar in these populations, the relationship between these factors and downstream mental health symptoms may yet be different between these groups. For example, tentative evidence would suggest that the interrelationship between complex trauma and shame is particularly complicated and salient with regard to self-harm (Dyer et al., 2013; Smyth, Kouros, \& Meuret, 2014). 
The relationships between state shame and coping styles across the groups were also interesting. The predominance of "Attack self” as a predictor of increased state shame across the Complex Trauma, General Mental Health, and Healthy Volunteers groups is concordant with theoretical understanding and recent empirical evidence. “Attack self” is a toxic coping style in which feelings of humiliation and shame morph into anger that is directed inward as extreme self-criticism, self-disgust, and negative self-evaluation (Nathanson, 1992).

Numerous theoretical perspectives would support the notion that negative self-appraisals and self-attack coping behaviours in response to shame-inducing situations are more likely to perpetuate and exacerbate shame feelings in given scenarios rather than ameliorate them (e.g., Ehlers \& Clark, 2000; Tracy \& Robins, 2007). The evidence in the present study supports this view that "attack self” is a particularly unhelpful coping style for managing shame and may be a significant risk factor for subsequent psychological distress. Moreover, this process seems to be present across trauma, general mental health, and healthy volunteers, indicating a common psychological mechanism. Recent research supports these findings with self-attack and self-criticism manifesting as prominent negative shame coping strategies in multiple populations and predicting mental health difficulties as varied as social anxiety, general anxiety, stress, depression, and poor intimate relationship functioning (Dorahy et al., 2014; Gilbert et al., 2011; Shahar, Doron, \& Szepzenwol, 2014). The fact that self-criticism, negative core schemata, and the traumatic experiences shaping Complex Trauma and DID reactions are thought to emerge from early childhood are also suggestive of overlapping pathways (Dalenberg et al., 2012; Kopala-Sibley, Zuroff, Hankin, \&, Abela, 2015).

In contrast, the DID group, while exhibiting elevated "attack self” coping relative to the other groups, demonstrated a different coping style-state shame relationship. The primary coping style that was predictive of elevated state shame was "withdrawal”. Although this is noticeably distinct from the other three groups, it is perhaps predictable. "Withdrawal” refers 
to the instinct to retreat and remove oneself from shame-provoking stimuli (including other people) to attain a perceived sense of safety from shame feelings. As stated, in many ways, dissociation represents a global “withdrawal” strategy in response to stress, and therefore individuals with DID may naturally engage in such methods of coping. However, as with pathological dissociation, although such a coping strategy can yield short-term benefits, in the longer term this may ultimately intensify psychological distress by not allowing any exposure and modification of it. Ironically, “withdrawal” was initially asserted as a psychologically healthy shame coping style (see Nathanson, 1992). Gathering empirical evidence has provided a different picture of this coping style and found that it is both a problematic coping strategy for DID and a risk factor for difficulties in both forming effective therapeutic relationships and overall relationship functioning (Black et al., 2013; Dorahy et al., 2014). Moreover, “withdrawal” was the only coping style that both the Complex Trauma and General Mental Health groups had significantly higher levels of compared to Healthy Volunteers, further highlighting its potentially detrimental role in psychopathology.

It is worth commenting on the consistent lack of significance obtained in the group comparisons and regressions involving the "attack other" coping style, which was stark in comparison to the overall group differences on the other shame management styles. Although a notable exception, this finding is somewhat consistent with the research literature. Several investigations examining shame, trauma and mental health have found that the more dominant means of managing shame is to turn this self-conscious emotion inwards or try to avoid its activation, rather than discharging the feeling onto others (Dyer et al., 2013; Gilbert et al., 2010). Another consideration is that social desirability has been a noted feature when assessing trauma, anger, and aggression (see Dyer et al., 2009), and therefore the low levels of “attack other” could partially reflect this response bias. 
Understanding the relationships between shame coping styles and other psychological factors has important clinical implications. It is apparent that "attack self” coping is a common behavioural response in mental health presentations that negatively affects shame reactions and, in all likelihood, subsequent psychological wellbeing. Moreover, levels of shame coping styles were similar in both Complex Trauma and General Mental Health groups, indicating these presentations have somewhat similar shame processes. In contrast, the "withdrawal” coping style seems more salient to the DID population. Therefore comprehensive assessment of shame coping style could be important in understanding the mechanisms of mental health presentations and contribute to a more comprehensive formulation of individual client difficulties. Linked to this, the differential role of "attack self” and "withdrawal” in presentations can inform clinical decision-making and future treatment development. For example, modification of "attack self” coping styles may be important in resolution of shame reactions in trauma populations. Emerging interventions such as Acceptance and Commitment Therapy and Compassion-focussed Therapy, which have been evidenced as successful in defusing "attack self” appraisals and behaviour patterns may be useful in such treatment protocols (e.g., Gilbert, 2010; Luoma \& Platt, 2015).

The integration of compassion-focussed and shame interventions into trauma therapy is an important avenue of future empirical and clinical consideration. Currently, new models of treatment for childhood sexual abuse and complex trauma (e.g., STAIR Narrative Therapy; Cloitre et al., 2014) incorporate emotional regulation strategies and coping skills in the initial phases of therapy to provide a stable base for clients to then engage in later trauma processing. Bearing in mind the unhelpful role of some shame coping styles observed in the current study and recent findings that shame responding can be a barrier to the therapeutic alliance (Black et al., 2013), the integration of shame interventions at these early therapeutic stages would be beneficial. 
Considering this study was a largely exploratory, cross-sectional evaluation of shame in clinical populations, there are several limitations that should be considered when making inferences. Firstly, although some of the unexpected results obtained in this investigation (e.g., similarity between the Complex Trauma and General Mental Health group level of shame) have been explained above in terms of psychological mechanisms, it must be acknowledged that these findings may also have emerged as a result of contentions within the shame literature regarding accepted theoretical models of shame. Debate continues within the literature as to whether shame has primarily evolutionary, social-evaluative, or sociocultural origins, as well as whether it is a generally adaptive or maladaptive phenomenon (Wong \& Tsai, 2007). The controversy surrounding the construct of shame has led to inconsistent operational definitions and measurement tools being applied in the research field. The current investigation utilised the SSGS and COSS; two measures that arose from different theoretical positions on the nature of shame (see Nathanson, 1992; Tangney \& Dearing, 2002). It is therefore possible that the present results are partially reflective of the lack of consistency within the literature. Certainly, the field would be improved by greater clarity in the conceptualisation of shame and the future development of more robust measurement tools.

Secondly, the representativeness of the sample is hampered by omissions and errors in collection of demographic information, with between-group differences emerging on some factors (e.g., gender). Moreover, the clinical group data was gathered from different countries (i.e., Australia, Northern Ireland) with potentially different cultural shame responding. However, it must also be acknowledged that preliminary analyses revealed no confounding effects of the demographic differences on dependent variables of interest. Also, the countries/cultures from which the data originated share more similarities than differences in many respects (i.e., western, first world, individualistic etc.). Secondly, the lack of available trauma, mental health and PTSD assessment for the participant groups also limits 
conclusions. Trauma and PTSD information was available for some groups (e.g., Complex Trauma); however, it was not available for analysis due to local ethical restrictions in the use of patient data. Furthermore, the present study was focused purely on shame coping style and state shame comparisons, rather than wider clinical symptoms, which limits interpretations concerning the role of shame in overall psychological wellbeing. Lastly, the sample size of the current investigation was quite large with a high level of statistical power, but numbers obtained in the DID group were lower relative to the other groups.

Future research would benefit from comparing more clinical groups on shame coping styles and extending comparisons to additional variables such as trait shame and psychological distress (e.g., depression, anxiety). This way a fuller understanding of the patterns of shame across populations and how they interact with psychopathology can be achieved. Similarly, intervention studies examining how discrete treatment factors target shame processes and coping styles would also advance this clinical area (e.g., Gilbert, 2010).

In conclusion, levels of shame coping styles and state shame were significantly different across the four populations examined in the study, with the DID group exhibiting markedly higher levels of "attack self”, “withdrawal”, and “avoidance” relative to the other groups. The Complex Trauma and General Mental Health groups had comparable levels of state shame, guilt and pride, and shame coping styles, suggesting these populations may not be as different as previously thought on shame processes. Both groups had elevated levels of shame coping and state shame compared to the normative sample. “Attack self” emerged as the most salient coping style predictive of increased state shame in the Complex Trauma, General Mental Health, and health Volunteer groups, whereas “withdrawal” was the sole predictor of state shame in the DID group. These differential profiles of shame coping - state shame may have assessment and treatment implications. Larger scale investigations with more robust research designs should expand on these initial findings. 


\section{References}

American Psychiatric Association (1994). Diagnostic and Statistical Manual of Mental Disorders (4th ed.). Washington, DC: APA.

Black, R., Curran, D., \& Dyer, K. F. W. (2013). The impact of shame on the therapeutic alliance and intimate relationships. Journal of Clinical Psychology, 69, 646 - 654.

Chu, J. A. (2011). Rebuilding Shattered Lives: Treating Complex PTSD and Dissociative Disorders $2^{\text {nd }}$ ed. New York: Wiley.

Cloitre, M., Henn-Haase, C., Herman, J. L., Jackson, C., Kaslow, N, Klein, C., Mendelsohn, M. \& Petkova, E. (2014). A multi-site single-blind clinical study to compare the effects of STAIR Narrative Therapy to treatment as usual among women with PTSD in public sector mental health settings: study protocol for a randomized controlled trial. Trials, 15. doi:10.1186/17456215-15-197

Cooper, C. (2010). Individual differences and personality. London: Routledge.

Courtois, C. A. \& Ford, J. A. (2013). Treatment of complex trauma. London: Guilford Press.

Dalenberg, C. J., Brand, B. L., Gleaves, D. H., Dorahy, M. J., Loewenstein, R. J., Cardena, E., Frewen, P. A., Carlson, E. B., \& Spiegel, D. (2012). Evaluation of the evidence for the trauma and fantasy models of dissociation. Psychological Bulletin, 138, 550 - 588.

Dorahy, M. J., (2010). The Impact of Dissociation, Shame, and Guilt on Interpersonal Relationships in Chronically Traumatized Individuals: A Pilot Study. Journal of Traumatic Stress, 23, 653 $-656$.

Dorahy, M. J., Brand, B. L., Şar, V., Krüger, C., Stavropoulos, P., Martínez-Taboas, A., LewisFernández, R., \& Middleton, W. (2014). Dissociative identity disorder: An empirical overview. Australian and New Zealand Journal of Psychiatry, 48, 402 - 417. 
Dorahy, M.J., Corry, M., Shannon, M., MacSherry, A., Hamilton, G., McRobert, G., Elder, R., \& Hanna, D. (2009). Complex PTSD, interpersonal trauma and relational consequences: Findings from a treatment-receiving Northern Irish sample. Journal of Affective Disorders, $112,71-80$.

Dorahy, M. J., Corry, M., Shannon, M., Webb, K., McDermott, B., Ryan, M., \& Dyer, K. F.

W. (2013). Complex trauma and intimate relationships: The impact of shame, guilt and dissociation. Journal of Affective Disorders, 147, 72-79. Doi: doi.org/10.1016/j.jad.2012.10.010

Dorahy,M. J., Middleton, W., Seager, L., McGurrin, P., Williams, M., \& Chambers, R. (2015). Dissociation, shame, complex PTSD, child maltreatment and intimate relationship selfconcept in dissociative disorder, chronic PTSD and mixed psychiatric groups. Journal of Affective Disorders, 172, 195 - 203.

Dyer, K. F. W., Dorahy, M., Shannon, M., \& Corry, M. (2013). Trauma typology as a risk factor for aggression and self-harm in a complex PTSD population. Journal of Trauma and Dissociation, 14, 56 - 68 .

Ehlers, A. \& Clark, D. M. (2000). A cognitive model of posttraumatic stress disorder. Behaviour Research and Therapy, 38, 319 - 345.

Elison, J., Lennon, R. \& Pulos, S. (2006). Investigating the compass of shame: The development of the compass of shame of scale. Social Behavior and Personality, 34, 221-238.

Fergus, T. A., Valentiner, D. P., Mcgrath, P. B., \& Jencius, S. (2010). Shame- and guilt-proneness: Relationships with anxiety disorder symptoms in a clinical sample. Journal of Affective Disorders, 24, $811-815$.

Ferry, F., Brady, S. E., Bunting, B., Murphy, S. D., Bolton, D. \& O'Neill, S. (2015) The economic burden of PTSD in Northern Ireland. Journal of Traumatic Stress, 28, 191 -197. 
Finkelhor, D. \& Browne, A. (1985). The traumatic impact of childhood sexual abuse: a conceptualisation. American Journal of Orthopsychiatry, 55, 530 - 541.

Ford, J. D., Hawke, J., Alessi, S., Ledgerwood, D., \& Petry, N. (2007). Psychological trauma and PTSD symptoms as predictors of substance dependence treatment outcome. Behaviour Research and Therapy, 45, 2417-2431.

Gilbert, P. (2002). Evolution, social roles, and differences in shame and guilt. Cognitive Therapy: An International quarterly, 16, 263 - 294.

Gilbert, P. (2010). Compassion-focussed Therapy. London: Routledge.

Gilbert, P., McEwan, K., Gibbons, L., Chotal, S., Duarte, J., \& Matos, M. (2011). Fears of compassion and happiness in relation to alexithymia, mindfulness, and self-criticism. Psychology and Psychotherapy: Theory, Research, and Practice, 85, 374 - 390.

Gilbert, P., McEwan, K., Irons, C., Bhundia, R., Christie, R., Broomhead, C. \& Rockliff, H. (2010). Self-harm in a mixed clinical population: The roles of self-criticism, shame, and social rank. British Journal of Clinical Psychology, 49, 563 - 576.

Herman, J. (2015). Trauma and recovery. London: Pandora

Kim, J., Thibodeau, N. L., \& Jorgensen, D. (2014). Childhood abuse and current interpersonal conflict: The role of shame. Child Abuse and Neglect, 33, 362 - 371.

Kopala-Sibley, D. C., Zuroff, D. C., Hankin, B. L., Abela, J. R. Z. (2015). The development of selfcriticism and dependency in early adolescence and their role in the development of depressive and anxiety symptoms. Personality and Social Psychology Bulletin, 41, 1094 1109.

Leskela, J., Dieperink, M., \& Thuras, P., 2002. Shame and posttraumatic stress disorder. Journal of Traumatic Stress, 15, 223 - 226. 
Luby, J., Belden, A., Sullivan, J., Hayen, R., McCadney, A., \& Spitznagel, E. (2009) Shame and guilt in preschool depression: evidence for elevations in self-conscious emotions in depression as early as age three. Journal of Child Psychology and Psychiatry, 50, 1156 1166.

Luoma J. B., \& Platt, M. G. (2015). Shame, self-criticism, self-stigma, and compassion in Acceptance and Commitment Therapy. Current Opinion in Psychology, 2, 97 - 101.

Marshall, D.E., Sanftner, J.L. \& Tangney, J.P. (1994). The state shame and guilt scale. Fairfax: George Mason University.

Nathanson, D. L., (1992). Shame and Pride: Affect, sex, and the birth of the self. New York: Norton.

Oktedalen, T., Hoffart, A., \& Langkaas, T. F. (2015). Trauma-related shame and guilt as timevarying predictors of posttraumatic stress disorder symptoms during imagery exposure and imagery rescripting-A randomized controlled trial. Psychotherapy Research, 25, 518 - 532.

Pelcovitz, D., Van der Kolk, B., Roth, S., Mandel, F., Kaplan, S., \& Resick, P. (1997). Development of a criteria set and a Structured Interview for Disorders of Extreme Stress (SIDES). Journal of Traumatic Stress, 10, 3 - 15.

Petrides, K. V. \& Furnham, A. (2003). Trait emotional intelligence: Behavioural validation in two studies of emotion recognition and reactivity to mood induction. European Journal of Personality, 17, $39-57$.

Putnam, F. W. (2006). Dissociative disorders. In D. Cicchetti and D. J. Cohen (Eds), Developmental Psychopathology, Volume 2 (pp. 657 - 695). New York: Wiley.

Robinaugh, D. J. \& McNally, R. J. (2010). Autobiographical memory for shame or guilt provoking events: Association with psychological symptoms. Behaviour Research and Therapy, 48, 646 $-652$. 
Ross, C. A., Heber, S., Norton, G. R., Anderson, D., Anderson, G., Barchet, P. (1989). The Dissociative Disorders Interview Schedule: a structured interview. Dissociation, 2, 169 172.

Shahar, B., Doron, G., \& Szepzenwol, O. (2014). Childhood maltreatment,shame-proneness, and self-criticism in social anxiety disorder: A sequential mediational model. Clinical Psychology and Psychotherapy. DOI: 10.1002/cpp.1918

Smyth, N. B. Kouros, C. D. \& Meuret, A. E. (2014). The Role of Trauma Symptoms in Nonsuicidal Self-Injury. Trauma, Violence, and Abuse, 15, 41 - 56.

Srinivas, T., DePrince, A. P., \& Chu, A. T. (2015). Links between posttrauma appraisals and traumarelated distress in adolescent females from the child welfare system. Child Abuse \& Neglect. http://dx.doi.org/10.1016/j.chiabu.2015.05.011

Tangney, J. P. \& Dearing, R. (2002). Shame and Guilt. New York: Guilford Press.

Tangney, J. P., Stuewig, J., \& Mashek, D. (2007). Moral emotions and moral behavior. Annual Review of Psychology, 58, 345 - 372.

Tomkins, S. S. (1963). Affect, imagery, consciousness. Volume 2: The negative affects. New York, NY: Springer.

Tracey, L. J., \& Robins, R. W. (2007). The self in self-conscious emotions: A cognitive appraisal approach. In J. L. Tracy, R. W. Robins, \& J. P. Tangney, (Eds.), The self-conscious emotions. Theory and Research (pp. 3 -20). London: Guilford Press.

Wong, Y. \& Tsai, J. L. (2007). Cultural models of shame and guilt. In J. Tracy, R. Robins \& J. Tangney (Eds.). Handbook of Self-Conscious Emotions (pp. 210 - 223). New York: Guilford Press. 
Table 1. Sample descriptive statistics

\begin{tabular}{|c|c|c|c|c|}
\hline & $\begin{array}{c}\text { DID } \\
(\mathrm{N}=20)\end{array}$ & $\begin{array}{l}\text { Complex Trauma } \\
\qquad(\mathrm{N}=65)\end{array}$ & $\begin{array}{c}\text { General Mental } \\
\text { Health } \\
(\mathrm{N}=41)\end{array}$ & $\begin{array}{c}\text { Healthy } \\
\text { Volunteer } \\
(\mathrm{N}=125)\end{array}$ \\
\hline \multicolumn{5}{|l|}{ Gender } \\
\hline Male & $0 \%$ & $68 \%$ & $54 \%$ & $19 \%$ \\
\hline Female & $100 \%$ & $32 \%$ & $46 \%$ & $81 \%$ \\
\hline Mean Age (SD) & $45.6(9.4)$ & $40.4(12.4)$ & $41.3(12.5)$ & - \\
\hline \multicolumn{5}{|c|}{$\begin{array}{l}\text { Marital/relationship } \\
\text { status }\end{array}$} \\
\hline Single & $40 \%$ & - & $56 \%$ & - \\
\hline Married & $25 \%$ & - & $24 \%$ & - \\
\hline Separated/ & $35 \%$ & - & $20 \%$ & - \\
\hline Divorced & & & & \\
\hline
\end{tabular}


Table 2. Participant group means on shame/guilt/pride state subscales and coping style subscales

\begin{tabular}{lllll}
\hline & $\begin{array}{l}\text { DID } \\
(\mathrm{N}=20)\end{array}$ & $\begin{array}{l}\text { Complex Trauma } \\
(\mathrm{N}=65)\end{array}$ & $\begin{array}{l}\text { General Mental Health } \\
(\mathrm{N}=41)\end{array}$ & $\begin{array}{l}\text { Healthy Volunteer } \\
(\mathrm{N}=125)\end{array}$ \\
\hline $\begin{array}{llll}\text { SSGS } \\
\text { State shame }\end{array}$ & $15.65^{\mathrm{abc}}$ & $12.37^{\mathrm{d}}$ & $11.07^{\mathrm{e}}$ & 7.38 \\
State guilt & $14.50^{\mathrm{c}}$ & $13.32^{\mathrm{d}}$ & $12.68^{\mathrm{e}}$ & 8.06 \\
State pride & $9.55^{\mathrm{bc}}$ & $11.43^{\mathrm{d}}$ & $13.12^{\mathrm{e}}$ & 16.26 \\
& & & & \\
COSS & & & $30.10^{\mathrm{e}}$ & 22.81 \\
Withdrawal & $48.75^{\mathrm{abc}}$ & $34.76^{\mathrm{d}}$ & 30.49 & 25.64 \\
Attack self & $50.05^{\mathrm{abc}}$ & $34.58^{\mathrm{d}}$ & 16.46 & 16.80 \\
Attack other & 21.65 & 18.98 & 18.93 & 21.41 \\
Avoidance & $32.50^{\mathrm{abc}}$ & 21.75 & & \\
& & & & \\
\hline
\end{tabular}

${ }^{\mathrm{a}}$ DID $>$ Complex Trauma; $\mathrm{p}<.05$

${ }^{\mathrm{b}}$ DID $>$ General Mental Health; $\mathrm{p}<.05$

'DID $>$ Healthy Volunteer; $\mathrm{p}<.05$

${ }^{\mathrm{d} C}$ Complex Trauma $>$ Healthy volunteer; $\mathrm{p}<.05$

${ }^{\mathrm{e}}$ General Mental Health $>$ Healthy Volunteer; $\mathrm{p}<.05$ 
Table 3. Summary of stepwise multiple regressions for coping style predictors of state shame in separate groups

$\begin{array}{lllll}\text { B } & S E \text { B } & \text { B } & R^{2} & \text { Sig. (p) }\end{array}$

DID Group

"Withdrawal"

Complex Trauma Group

“Attack Self”

General Mental Health Group

“Attack Self”

Healthy Volunteer Group

“Attack Self”
.65

.15

.72

.52

$<.001$

.2

$<.001$

$.25 \quad .06$

.44

$<.001$

.36

$<.001$

.22

.05

.6

$<.001$

.28

$<.001$

.18

.03

.53

$<.001$ 